Session TA2-4

\title{
Living with the Lab: A Project-Based Curriculum for First-Year Engineering Students
}

\author{
Stan Cronk, David Hall, James Nelson \\ Louisiana Tech University
}

\begin{abstract}
The freshman engineering course sequence has been completely revised with support from an NSF CCLI grant. The mission of the curriculum is to instill the attributes of "The Engineer of 2020 " in our students. We have structured the content timing and delivery so that the knowledge, skills and attitudes associated with each curriculum thread are built progressively throughout the year. The curriculum objectives were developed around the ten attributes of engineers outlined in the National Academy of Engineering report "The Engineer of 2020: Visions of Engineering in the New Century." The project-based nature of the curriculum we call "Living with the Lab" lends itself to the development of many of the attributes of The Engineer of 2020. Our aim is to create innovative students with a can-do spirit through a project-based curriculum where students repeatedly apply technology and fundamental engineering skills to solve problems.
\end{abstract}

The curriculum objectives are divided into seven threads that run concurrently throughout the year, including: systems, electromechanical devices, fabrication and acquisition, software, fundamental engineering concepts, communication, and broadening activities. Instead of a textbook, students purchase the following items for the freshman classes:

- Parallax Boe-Bot kit for the development of skills in programming and prototyping circuits (current cost: \$109). The Boe-Bot kit comes with a platform for a BASIC STAMP microcontroller, a small breadboard, an assortment of electronic parts such as photoresistors and LEDs, a chassis, servo motors, and wheels to facilitate projects requiring mobility, a manual that allows students to complete the assembly of the BoeBot kit and many programming and circuit projects independently.

- Tools for completing electromechanical projects (current cost: \$60-\$100). Students purchase a variety of tools, including safety glasses, a multimeter, a dial caliper, Teflon tape, and other miscellaneous tools and parts needed to complete projects throughout the first year of engineering classes.

- Software for facilitating engineering analysis and 3D modeling. All freshmen engineering students purchase laptop computers for independent work in and out of the classroom. They are also required to purchase MathCad, SolidWorks, a spreadsheet, and presentation software. The purchase of Microsoft EXCEL and PowerPoint are encouraged, but not required.

The students are challenged by the curriculum, but are more motivated and engaged in learning than with the previous curriculum. Assessments conducted each quarter ensure that the curriculum accomplishes our goal of preparing students to meet the attributes of "The Engineer of 2020.” 


\section{Introduction}

Project-based freshman engineering curricula began in the 1990s due in large part to the NSF Engineering Education Coalitions ${ }^{1-4}$. This trend towards hands-on freshman engineering programs with a significant design component continues today at a variety of universities across the country ${ }^{5-7}$. There is a significant amount of literature on the subject that shows many benefits of incorporating project-based instruction with design early and often within engineering curricula $^{1-11}$.

In traditional laboratory settings, faculty members must make sure that the required equipment is ready and that supplies are on hand so that prototypes can be constructed or data can be acquired. While energetic faculty members sometimes can and do guide students through creative design projects and laboratory experiences, accomplishing this task over a long period of time and with a large number of students is difficult and may not be sustainable.

The College of Engineering and Science at Louisiana Tech University has implemented a freshman engineering curriculum called "Living with the Lab." The new curriculum seeks to achieve a major increase in experiential learning in a way that is sustainable by putting the ownership and maintenance of the "laboratory" into the hands of the students. Student-owned laboratories facilitate frequent hands-on learning and build the knowledge, skills and spirit that lead to innovation. This paper describes the new curriculum along with faculty training activities and assessment results.

\section{The Freshman Engineering Curriculum}

In 1998 the College of Engineering and Science moved to an integrated engineering curriculum based on the educational practices of the National Science Foundation Educational Coalitions ${ }^{12}$. Along with our freshman engineering course sequence, our freshman integrated curriculum includes differential and integral calculus courses, basic chemistry lecture and laboratory courses, and a calculus-based physics course; students also typically enroll in several nontechnical courses during the freshman year. The freshman integrated courses are taken in "blocks" so that classes of 40 students share the same sections of each mathematics, science and engineering course during each quarter. The topics presented in the mathematics and science courses are coordinated to some degree with the topics presented in the engineering courses to motivate student learning and to provide for content overlap. The three engineering courses (ENGR 120, 121 and 122) are implemented as combined lecture / laboratory classes and meet twice a week for 110 minutes per meeting.

The freshman engineering course sequence, as taught between 1998 and the spring of 2007, included engineering fundamentals (circuits, materials balance, and statics), computer applications (Excel, MathCAD, and Solid Edge), statistics, engineering economics, teamwork, communication skills, and a design project. The students did most of their work in teams, including homework problems, laboratory activities, and presentations. The year culminated in a design competition between ENGR 122 teams. 
With seed money provided by the university to purchase course supplies, we began what would eventually become the Living with the Lab freshman course sequence in 2002 with a group of 21 students who volunteered to participate in the new courses. The new courses shared many similarities with their predecessors, but contained a much stronger project focus. For the next three academic years, the new courses were offered to two groups of 20 honors engineering students each year. Funding from an NSF Course, Curriculum and Laboratory Improvement grant allowed us to extend the curriculum to all 280 freshman engineering students taking ENGR 120 beginning in the fall of 2007. Approximately 800 freshman students have enrolled in the course sequences based on the Living with the Lab curriculum from 2007 through the winter quarter of the 2008-09 academic year.

\section{Faculty Training}

In the summer of 2007, we offered a two-week, in-house faculty training workshop for six faculty members who would be teaching the freshman engineering courses. Each participant received their own Boe-Bot kit and worked through the same in-class and homework assignments that students would be expected to complete. They fabricated centrifugal pumps, RTDs, conductivity sensors, and fish tank systems. The workshop also introduced the faculty to the philosophy of the Living with the Lab curriculum, which may often involve switching from one topic to another several times during a single class period. Spending two weeks together to focus on the curriculum provided for close bonding between the workshop participants, allowing us to build a strong team with open communication. We continue to meet weekly as we work together to deliver and improve the curriculum.

\section{The "Engineer of 2020" Project}

In 2001-02, the National Academy of Engineering established “The Engineer of 2020" Project, which sought to develop a vision for the engineering field and to predict the work environment of an engineer in $2020^{13}$. The report resulting from Phase 1 of this work identified ten key attributes to support the relevance of the engineering profession in 2020 and beyond. These attributes are presented in Table 1.

Table 1. Key attributes that the "Engineer of 2020" should possess ${ }^{13}$

\begin{tabular}{|l|l|}
\hline No. & Attribute \\
\hline A1. & Strong analytical skills \\
\hline A2. & Practical ingenuity \\
\hline A3. & Creativity \\
\hline A4. & Good communication skills \\
\hline A5. & Lifelong learners \\
\hline A6. & Dynamic, agile, resilient and flexible characteristics \\
\hline A7. & High ethical standards \\
\hline A8. & Leadership skills \\
\hline A9. & Professionalism \\
\hline A10. & Business and management skills \\
\hline
\end{tabular}

Proceedings of the 2009 ASEE Gulf-Southwest Annual Conference Baylor University

Copyright $\Subset$ 2009, American Society for Engineering Education 
To provide a set of guideposts to help us determine if our strategies were effective not only in teaching students, but also in preparing them for their engineering careers, we selected the attributes of "The Engineer of 2020," realizing that these attributes offered a close match with our efforts. We began mapping our objectives to The Engineer of 2020 attributes, discarding objectives that didn't match well and adding objectives and activities to increase consonance with those attributes. For example, we determined that our students needed to participate in more professional development activities. We therefore boosted the requirement that students attend professional society meetings sponsored by the College of Engineering and Science from five per year to fifteen per year.

\section{Living with the Lab}

\section{The Living with the Lab Concept}

Our faculty members have found that when teaching traditional laboratory and shop classes, making certain that all necessary equipment and supplies are ready before class can be difficult. Sustaining this effort with large numbers of students over time may not be sustainable. Assignment of projects to students or student groups who have purchased their own robotics kits makes it possible for the "laboratory" or "design platform" to travel with the students to the places where they spend their time - their dorm rooms or apartments, or even the local coffee shop. When students control and maintain their own hardware, significant increases in experiential learning is possible; students are living with the lab. The end result is more hands-on student activity without an excessive investment of faculty time.

\section{The Living with the Lab Curriculum}

The major aim of the Living with the Lab curriculum is to create innovative students with a cando spirit through a project based curriculum where students repeatedly apply technology and fundamentals to solve problems. The new curriculum boosts experiential learning by putting the ownership and maintenance of the "lab" into the hands of the students. Each student must purchase a robotics kit ( $\sim 110)$ with a programmable controller, sensors, servos, and software, along with a toolkit $(\sim 70)$ that together provide the basis for a mobile laboratory and design platform. A basic tenet of the curriculum is that student-owned labs motivate student learning and broaden the spectrum of projects and design topics that can be addressed, thus facilitating innovation.

\section{Objectives for the Freshman Engineering (Living with the Lab) Curriculum}

We have sought to implement a college-wide freshman course sequence focusing on "The Engineer of 2020" attributes A1 through A6 and to a lesser degree on the remaining attributes (A7-A10). The curriculum objectives are grouped into seven threads that span the freshman year, as shown in Figure 1. Linkages to the attributes of "The Engineer of 2020" (A1 through A10) are shown in parentheses after each objective. Each thread in the curriculum spans the entire freshman year. For example, every course has an engineering system that must be fabricated and tested, with the level of design involvement growing throughout the year as the project complexity increases. 
Students are administered end-of-quarter surveys to determine their level of confidence in meeting each of the course outcomes. By tying these outcomes to course objectives and compiling the results, student mastery of course outcomes and their confidence in further developing the attributes of The Engineer of 2020 can be indirectly measured. We are currently collecting course assessment data that will be tabulated at the end of the academic year to quantify how well we are fostering the desired attributes in our students. Tracking overall scores for each attribute over time will allow us to systematically examine and alter our curriculum to better achieve the desired attributes. Our goal in the freshman curriculum is to prepare the students as effectively as possible for engineering careers. 
SYSTEMS:

1. fabricate, test and evaluate the efficiency of an engineering system (A1,A2,A3,A6)

2. fabricate and test an engineering system where two physical parameters are controlled (A1,A2,A3,A6)

3. conceive, design, and fabricate a prototype utilizing a controller, sensors and actuators (A1,A2,A3,A6)

\section{ELECTROMECHANICAL:}

4. utilize a programmable controller that interfaces with selected sensors and actuators (A1,A2)

5. implement functional circuits on a solderless breadboard for sensing and control applications (A1,A2)

6. utilize multimeters to troubleshoot circuits and to determine the power usage of a device $(\mathrm{A} 1, \mathrm{~A} 2)$

7. describe the specifications, operating procedures, and underlying physics for the hardware utilized (A1,A2)

\section{FABRICATION AND ACQUISITION:}

8. fabricate parts using a wide range of conventional manufacturing processes (A2)

9. design and fabricate an RTD sensor using microfabrication processes (A1,A2)

10. locate materials, supplies and components in stores and from online suppliers (A2)

11. specify and purchase materials, supplies or components for projects (A2)

SOFTWARE:

12. utilize Excel, MathCAD and Solid Edge to assist in engineering analysis and design (A1,A2)

13. formulate and implement sequential computer programs for sensing and control applications $(\mathrm{A} 1, \mathrm{~A} 2)$

\section{FUNDAMENTALS:}

14. apply concepts of electricity and DC electric circuits (A1)

15. apply basic statistics to quantify and model experimental data (A1)

16. apply conservation of energy to engineering systems (A1)

17. apply basic chemistry and electrochemistry to salt water mixtures (A1)

18. apply conservation of mass to engineering systems (A1)

19. apply least squares fitting to calibrate sensors (A1)

20. apply concepts of statics to engineering systems (A1)

21. apply engineering economics to solve time value of money problems (A1)

\section{COMMUNICATION:}

22. utilize the specified engineering problem solving approach when completing assignments (A1,A4)

23. properly present technical information in tables and graphs (A4)

10.communicate the results of investigations and projects both orally and in writing (A4)

\section{BROADENING ACTIVITES:}

24. assess potential impacts of selected global and societal forces on our planet and its inhabitants (A5,A6,A7)

25. regularly attend professional society meetings and other student-led functions (A7,A8,A9)

26. work individually and collaboratively to complete course assignments (A4,A8)

27. apply creative problem solving techniques for product design (A3)

28. manage time and resources during the development of an innovative product (A10)

Figure 1. Curriculum Objectives of the Living with the Lab Curriculum. Linkages with the attributes of The Engineer of 2020 (see Table 1) are shown in parentheses. 


\section{Facilities and Resources}

The Freshman Projects Classroom is an 1800-square foot classroom that has been completely remodeled for teaching the new freshman engineering sequence of classes (see Figure 2). The classroom includes:

- 11 tables that seat 4 students each, with electrical outlets in the floor near each table;

- 1 desktop computer system at the front of the room for faculty use;

- 1 LCD projector and a 10 -foot projection screen;

- 2 portable lathes;

- 1 belt sander;

- 10 milling/drilling machines; and,

- ample cabinet space for storage of course tooling and supplies.

In addition, parts kits are provided to students which include, as needed, handheld drills, drill bits, and soldering irons, along with miscellaneous parts and accessories.

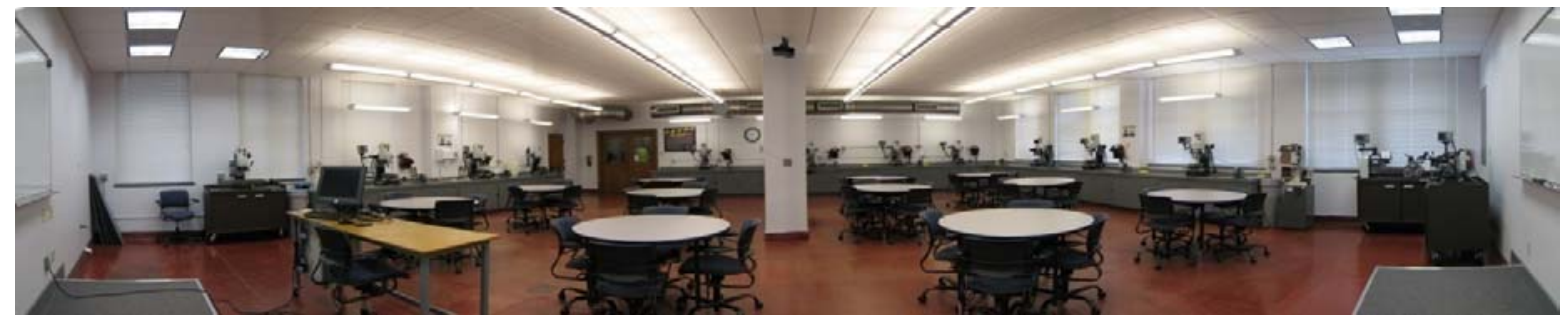

Figure 2. Layout of the integrated freshman classroom / laboratory / shop area.

Figure 2 shows the spacing of the milling / drilling machines. A single workstation with one of these machines is shown in Figure 3, along with a student who is working to fabricate the centrifugal pump, which is the project that drives the course content for ENGR 120.

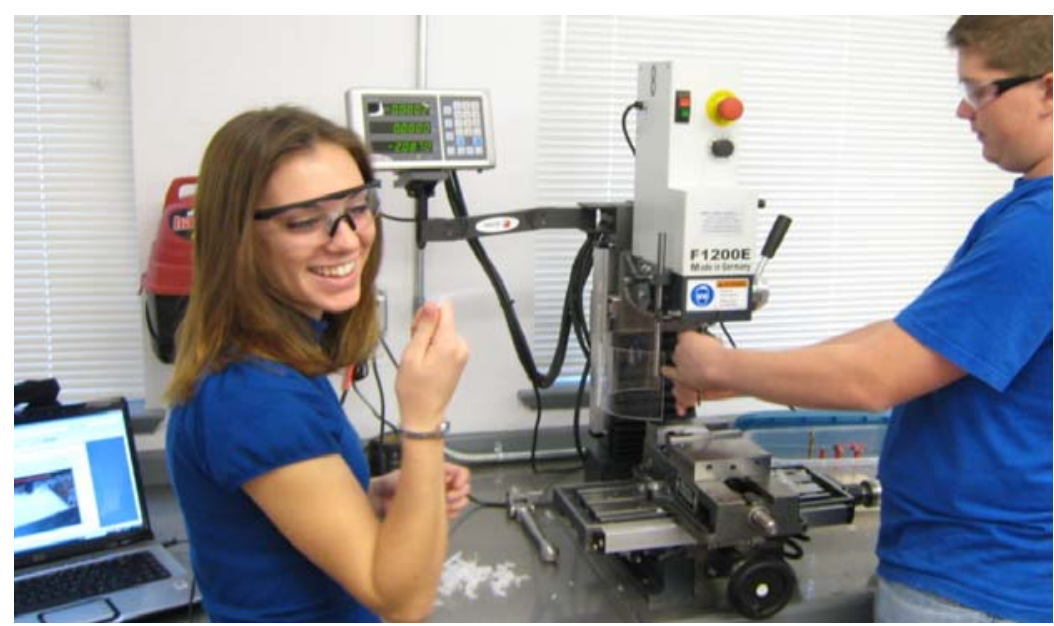

Figure 3. Students using a milling / drilling machine to fabricate a centrifugal pump.

Students use PowerPoint presentations provided by instructors to guide them through the fabrication process, allowing the student groups to work independently without the need for 
constant instructor supervision. The instructor will usually roam around the classroom to help student groups as needed. The course is structured so that the other half of the class performs an alternate activity when the milling / drilling machines are in use by the other students. In the case of the pump project, while half the students are performing fabrication activities, the others work on developing a 3D model of the pump assembly using a 3D modeling tool such as SolidWorks. Both the pump and the solid model are shown in Figure 4 to provide the reader with an idea of the type of project completed in the course.
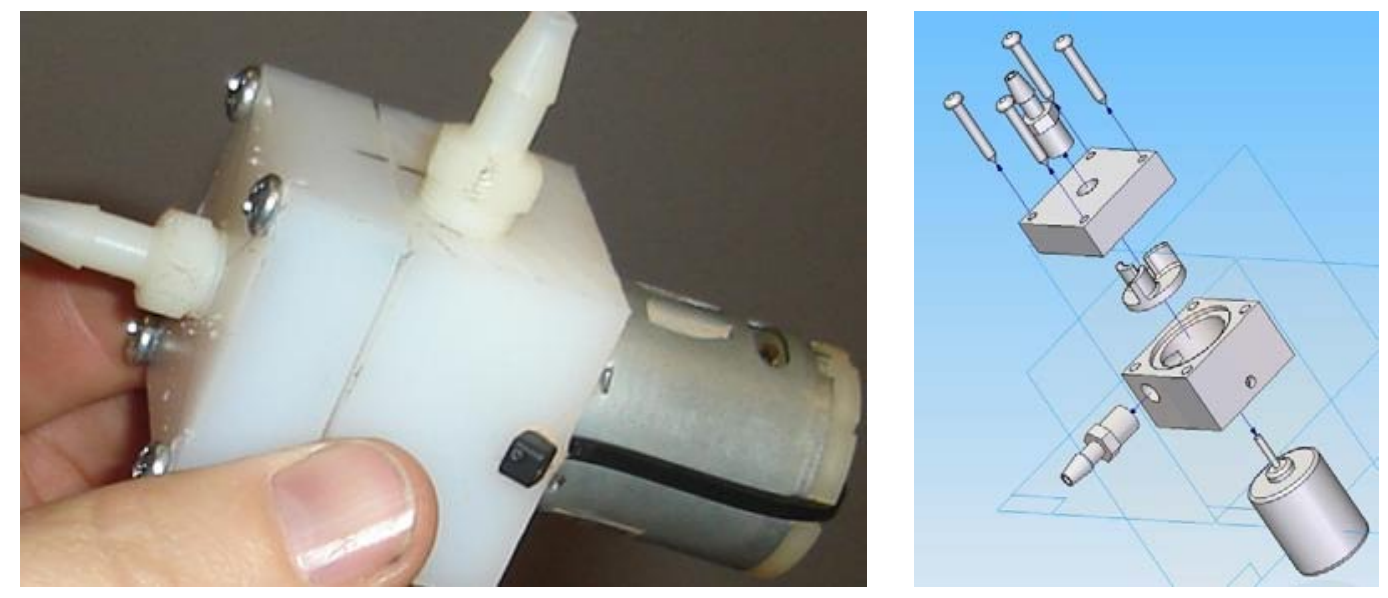

Figure 4. Centrifugal pump and its solid model.

The project in ENGR 121 is a fish tank project where students develop a system to control the temperature and salinity of a small volume of water. Students build almost the entire system from scratch, including the pump, the conductivity sensor, and a microfabricated resistance temperature detector (RTD). This course is almost entirely focused on presenting the fundamentals (salt water chemistry, conservation of mass, and conservation of energy), knowledge and skills required to implement the project.

Students are required to design a "smart product" as part of ENGR 122, the last of the three courses. Their design constraints include requirements for using the Boe-Bot along with at least one sensor. The student teams have a great deal of latitude in selecting the problem they want to solve, the strategies they test to solve the problem, and the complexity of the solutions. The students present the final versions for their projects at the Freshman Design Expo, where the projects are judged by teams of junior/senior engineering students and faculty members from the College of Engineering and Science and the College of Administration and Business.

\section{Results}

During the 2006-07 academic year, the Living with the Lab curriculum was tested in pilot sections of honors students one last time before being fully implemented throughout the College of Engineering and Science. Students enrolled in both the traditional ENGR 122 classes $(n=59)$ and the ENGR 122 Honors sections ( $\mathrm{n}=32$ ) were surveyed on how often they performed a variety of skill-based activities. Note that the only reason for selecting the honors group for the study is that the new LWTL curriculum was implemented across all honors sections during the 2006-07 
academic year. Therefore, the results from the survey reported in Tables 2 and 3 should only reflect the differences between the old and the revised curricula rather than differences between the capabilities of the students in honors and non-honors classes, because the "Living with the Lab" curriculum piloted with the honors students is the same as the curriculum now implemented for all students.

Table 2 shows a comparison of the number of hands-on activities reported by each group of students during the quarter.

Table 2. "Hands-on” Application Means by Course

\begin{tabular}{|l|r|r|}
\hline \multicolumn{1}{|c|}{ Application } & $\begin{array}{c}\text { ENGR } \\
\mathbf{1 2 2} \\
\text { (trad.) }\end{array}$ & $\begin{array}{c}\text { ENGR } \\
\text { (22H } \\
\text { (LWTL) }\end{array}$ \\
\hline Assembly & 3.10 & 11.19 \\
\hline Bending & 4.77 & 3.32 \\
\hline Cutting internal or external threads & .55 & 1.62 \\
\hline Drilling & 4.29 & 13.14 \\
\hline Implementing circuits on a & .62 & 21.73 \\
breadboard & 2.24 & 10.05 \\
\hline Layout & .09 & .36 \\
\hline Milling & .71 & .30 \\
\hline Rapid Prototyping & 2.05 & 7.77 \\
\hline Sawing & 2.17 & 13.83 \\
\hline Soldering & .17 & 2.71 \\
\hline Using a dial indicator & .06 & 1.17 \\
\hline Using a lathe & 2.28 & 3.55 \\
\hline Using a multimeter & 3.59 & 2.27 \\
\hline Using a scale & .02 & 20.23 \\
\hline Writing PBASIC programs & & \\
\hline
\end{tabular}

A Student's $t$-test on the "hands-on" application means in Table 2 demonstrates that the differences between the mean values are highly significant $(p=0.004181)$. We are confident that the project-based Living with the Lab curriculum is fulfilling our goal of providing the students with the practical experiences that they will need in their engineering careers.

Table 3 shows a comparison of the common course outcome performance means between the traditional curriculum and the Living with the Lab curriculum. Student responses could range from 1 (“completely unconfident”) to 6 (“completely confident”). 
Table 3. Comparison of Common Course Outcome Performance Means between the Traditional and the Living with the Lab Curricula

\begin{tabular}{|l|r|r|}
\hline \multicolumn{1}{|c|}{ Item } & \multicolumn{1}{|c|}{$\begin{array}{c}\text { ENGR } \\
\mathbf{1 2 0}\end{array}$} & \multicolumn{1}{|c|}{$\begin{array}{c}\text { ENGR } \\
\text { (trad.) }\end{array}$} \\
(LWTL) \\
\hline Utilize the prescribed solution format when solving problems. & 5.66 & 5.09 \\
\hline Work collaboratively with one or more other students. & 5.36 & 5.27 \\
\hline $\begin{array}{l}\text { Present the results of assignments and projects using written } \\
\text { communication. }\end{array}$ & 4.79 & 4.86 \\
\hline $\begin{array}{l}\text { Present the results of assignments and projects using oral } \\
\text { communication. }\end{array}$ & 3.91 & 4.42 \\
\hline $\begin{array}{l}\text { Generate 3D models of engineering components and assemblies } \\
\text { using Solid Edge. }\end{array}$ & 2.41 & 4.43 \\
\hline $\begin{array}{l}\text { Present technical data in tables and on graphs in a professional } \\
\text { manner. }\end{array}$ & 4.53 & 5.09 \\
\hline $\begin{array}{l}\text { Locate specifications and prices for the supplies, parts and systems } \\
\text { used in course projects from manufacturers and on-line retailers. }\end{array}$ & 3.15 & 5.01 \\
\hline Use linear regression analysis as appropriate in class projects. & 3.58 & 4.75 \\
\hline Utilize MathCAD to assist in solving engineering problems. & 1.32 & 4.97 \\
\hline Utilize Excel to assist in solving engineering problems. & 5.26 & 5.20 \\
\hline
\end{tabular}

A Student's t-test was performed to compare the performance means of the common course outcomes between the traditional and the Living with the Lab curricula. The performance means for the Living with the Lab curriculum were found to be significantly higher ( $p=0.025738)$ than those for the traditional curriculum. It can be seen in Table 3 that students in the traditional curriculum did master some of the course outcomes to a higher degree; this was in part due to the fact that more instructional time was provided for several of the outcomes.

We are convinced that the new project-based Living with the Lab curriculum is effective in offering the students many more opportunities to develop the skill sets associated with "The Engineer of 2020,” and we are enthusiastic about carrying this philosophy of blending theory with practical project-based experience to courses throughout the engineering disciplines.

\section{Conclusions}

A new project-based freshman curriculum has been implemented at Louisiana Tech University that includes three two-semester hour engineering courses. The new curriculum, called Living with the Lab, boosts experiential learning by putting the ownership and maintenance of the "lab" into the hands of the students. Each student purchases a Parallax Boe-Bot that provides a platform for laboratory and design exercises. Students begin the freshman year learning to program their robots to navigate based on input from various sensors. By the middle of the year, 
they are programming their microcontroller to regulate the temperature and salinity of a small volume using temperature and conductivity sensors that they fabricate and calibrate themselves. As the year passes, students learn engineering and science fundamentals as well as software, fabrication, communication, teamwork, and systems-level thinking skills. An increasing level of independence is expected as students fabricate and test projects that are increasingly complex and open-ended. The freshman year culminates in the Freshman Design Expo where student teams showcase prototypes of their smart products. Initial assessment results show large gains in hands-on learning relative to the previous curriculum.

\section{Acknowledgement and Disclaimer}

Partial support for this work was provided by the National Science Foundation's Course, Curriculum, and Laboratory Improvement (CCLI) program under Award No. 0618288. Any opinions, findings, and conclusions or recommendations expressed in this material are those of the authors and do not necessarily reflect the views of the National Science Foundation.

\section{References}

1. Richardson, J., Corleto, C., Froy, J., Imbrie, P.K., Parker, J., and R. Roedel, “Freshman Design Projects in the Foundation Coalition,” 1998 Frontiers in Education Conference, Tempe, Arizona, November 1998.

2. Hanesian, D., and A.J. Perna, “An Evolving Freshman Engineering Design Program - The NJIT Experience,” $29^{\text {th }}$ ASEE/IEEE Frontiers in Education Conference, November 10-13, San Juan, Puerto Rico, 1999.

3. Weggel, R.J., Arms, V., Makufka, M., and J. Mitchell, “Engineering Design for Freshman,” prepared for Drexel University and the Gateway Coalition,” February, 1998.

4. Sheppard, S. and R. Jenison, “Examples of Freshman Design Education,” International Journal of Engineering Education, 13 (4), 1997, 248-261.

5. Carlson, L., Sullivan, J., Poole, S., and M. Picket-May, "Engineers as Entrepreneurs: Invention and Innovation in Design and Build Courses,” $29^{\text {th }}$ ASEE/IEEE Frontiers in Education Conference, San Juan, Puerto Rice, 1999.

6. ITL (Integrated Teaching Laboratory), University Colorado at Boulder, 2008, http://itll.colorado.edu/ITLL/.

7. Hein, G.L. and S.A. Sorby, “Engineering Explorations: Introducing First-Year Students to Engineering,” $31^{\text {st }}$ ASEE/IEEE Frontiers in Education Conference, Reno, Nevada, October 21.

8. Splitt, F.G., "Systemic Engineering Education Reform: A Grand Challenge,” The Bent of Tau Beta Pi, Spring 2003.

9. Felder, R.M., “Changing Times and Paradigms,” Chemical Engineering Education, 38 (1), 2004, 32-33.

10. Carlson, L.W., and J.F. Sullivan, "Hands-on Engineering: Learning by Doing in the Integrated Teaching and Learning Program,” International Journal of Engineering Education, 15 (1), 1999, 20-31.

11. Cropley, D.H. and A. J. Cropley, “Fostering Creativity in Engineering Undergraduates,” High Ability Studies, The Journal of the European Council for High Ability, Carfax Publishing, Taylor \& Franic Ltd. UK, 11 (2), 2000, 207-219.

12. Nelson, J. and Napper, S., "Ramping Up to an Integrated Curriculum to Full Implementation.” Frontiers in Education, Puerto Rico, 1999.

13. National Academy of Engineering, “The Engineer of 2020.” The National Academies Press, Washington DC, 2004. www.nap.edu

STANLEY CRONK

Dr. Stan Cronk is a Lecturer in the Industrial Engineering Program at Louisiana Tech University. His teaching responsibilities are divided between Industrial Engineering and the Freshman Engineering curriculum.

Proceedings of the 2009 ASEE Gulf-Southwest Annual Conference Baylor University

Copyright (C) 2009, American Society for Engineering Education 
DAVID HALL

Dr. David Hall is an Associate Professor and Chair of the Mechanical Engineering Program at Louisiana Tech University. Dr. Hall is the director of the NSF CCLI grant which has funded much of this work.

JAMES NELSON

Dr. Jim Nelson is the Associate Dean of Undergraduate Studies and Professor of Civil Engineering in the College of Engineering and Science at Louisiana Tech University. 